\title{
A meta-model for soil carbon stock in agricultural soils
}

\author{
$\underline{\text { Z. Luo }}^{a}$, E. Wang ${ }^{\text {a }}$, B. Bryan ${ }^{\text {b }}$ \\ ${ }^{a}$ CSIRO Land and Water, Canberra, ACT 2601, Australia \\ ${ }^{b}$ CSIRO Ecosystem Sciences, Urrbrae, South Australia 5064, Australia \\ Email:zhongkui.luo@csiro.au
}

\begin{abstract}
Agricultural system models are frequently used to predict soil carbon (C) dynamics in agroecosystems at the field scale. Upscaling the results from those process-based models to assess the regional soil $\mathrm{C}$ change and sequestration potential is still a challenge due to the lack of detailed spatial information required. Meta-modelling could capture and summarize input-output relationships of systems models through simplified mathematical functions, and can significantly reduce the demand for input data required for initialization and parameterization of process-based models. Such a meta-model can be easily used for spatial assessment across regions. In this paper, we use the widely used Agricultural Production Systems sIMulater (APSIM) to generate simulation data, based on which we try to develop a simple meta-models for simulation of soil C changes across different regions in Australia. We run APSIM for 100 years (19072006) at 10 selected sites across the eastern Australia wheat-belt to generate soil $\mathrm{C}$ changes under a continuous wheat system. The 10 sites cover three annual rainfall patterns and a wide range of temperature and rainfall conditions, with mean annual rainfall in the wheat growth season ranging from 172 to $510 \mathrm{~mm}$, and mean annual temperature ranging from 7.2 to $18.5^{\circ} \mathrm{C}$. For each site, ten soils were used in the simulation to represent various soil types, with plant available water capacity (PAWC) ranging from 66 to $261 \mathrm{~mm}$. The meta-models predict soil C content at the end of the 100-year simulation $\left(C_{\text {content }}\right)$ and soil C changes from 1907 to 2006 ( $\left.C_{\text {change }}\right)$.
\end{abstract}

Our simulation results indicated that both $C_{\text {content }}$ and $C_{\text {change }}$ were significantly and positively related to the mean annual amount of retained residue. Residue production was significantly and positively related to PAWC and mean annual evapotranspiration, with the latter closely coupled with radiation $(R)$, temperature $(T)$ and precipitation $(P)$. APSIM simulation outputs at five randomly selected sites from the ten sites and step-wise multiple regressions were used to develop the meta-model. The meta-models of $C_{\text {content }}$ and $C_{\text {change }}$ with a residual error $\varepsilon$ are as follows:

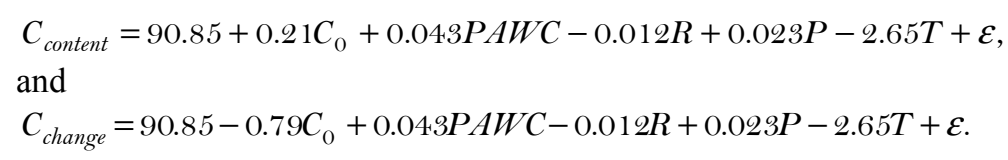

The two meta-models could explain $85 \%$ and $87 \%$ of the variation in C content and $\mathrm{C}$ change as simulated by APSIM, respectively. The two meta-models were validated using the modelled soil $\mathrm{C}$ values from APSIM at other five sites. It could explain $90 \%$ and $91 \%$ of the variation in $C_{\text {content }}$ and $C_{\text {change }}$ predicted by APSIM, respectively.

This simulation study suggested that the meta-model based on basic soil and climate data could capture the soil $\mathrm{C}$ dynamics in agricultural soils as good as the agricultural systems model APSIM. The meta-model significantly reduces the requirement of input data, and can easily be applied for regional or continental assessment of soil $\mathrm{C}$ changes.

Keywords: Soil carbon, plant available water capacity of soil (PAWC), precipitation, temperature, metamodel 


\section{INTRODUCTION}

Process-based biogeochemical models are widely used to estimate soil organic carbon (C) changes at field scale. Upscaling of these results from such models to regional or continental scales is still a challenge, because of uncertainties in the spatial variations in climate, soil and management conditions, and limited availability of detailed information across space (Falloon and Smith 2003, Saby et al. 2008, Ogle et al. 2010).However, soil $\mathrm{C}$ change for a given location and time period is the net balance between input and output that is controlled by some primary drivers (Beer et al. 2010, Mahecha et al. 2010). In agroecosystems, $\mathrm{C}$ input is driven by the fraction returned from primary production of crops as determined by climate/soil conditions and resource (e.g., water and nutrient) availability. Management practices further determine the fate of crop biomass thereby the subsequent $\mathrm{C}$ input into soil. $\mathrm{C}$ output from soil is primarily through decomposition, which is controlled by soil moisture, temperature, and soil characteristics regulating decomposer activity. If the soil $\mathrm{C}$ balance could be expressed as a simplified function of these drivers or a summary model, prediction of soil $\mathrm{C}$ changes at different spatiotemporal scales would be much easier. Such a summary model would greatly facilitate regional or continental predictions without needing the detailed information required for initialize process-based models.

"A simulation meta-model is a model of the simulation model, and exposes the fundamental nature of the system's input-output relationship through a simple mathematical function."(Santos and Santos 2007). Agricultural system models (with validated crop and soil modules) integrate the relevant drivers and processes to simulate crop growth and soil biogeochemical cycling. They can be used to extend experimental data and to generate responses of soil $\mathrm{C}$ to combinations of environmental and management conditions through scenario analysis. Based on the detailed simulation results, a meta-model can be derived by analyzing the model output and input data. Here, we aim to use the widely validated Agricultural Production Systems sIMulater (APSIM)(Keating et al. 2003, Wang et al. 2003) to generate scenario data on soil $\mathrm{C}$ responses to climate, soil and management conditions, and use these data to derive a simple metamodel to link soil $\mathrm{C}$ changes to the main drivers. The meta-model is then validated at five different sites, by comparing the simulated soil $\mathrm{C}$ changes with those from APSIM.

\section{MATERIALS AND METHODS}

\subsection{Study sites, climate and soil data and simulated cropping system}

Ten sites were selected within the wheat-belt of eastern Australia (Figure 1). These sites were selected to cover wide temperature and rainfall ranges as well as three annual rainfall patterns (uniform, winterdominated, and summer-dominated rainfall distributions). Daily historical climate data (1907-2006) at the ten sites were obtained from the SILO patched database (http://www.longpaddock.qld.gov.au/silo/). During the growth season of wheat crop from May to November, mean annual rainfall ranges from $172 \mathrm{~mm}$ at Emerald to $510 \mathrm{~mm}$ at Gambier, and mean annual temperature ranges from $7.2^{\circ} \mathrm{C}$ at Bendoc to 18.5 at Emerald.

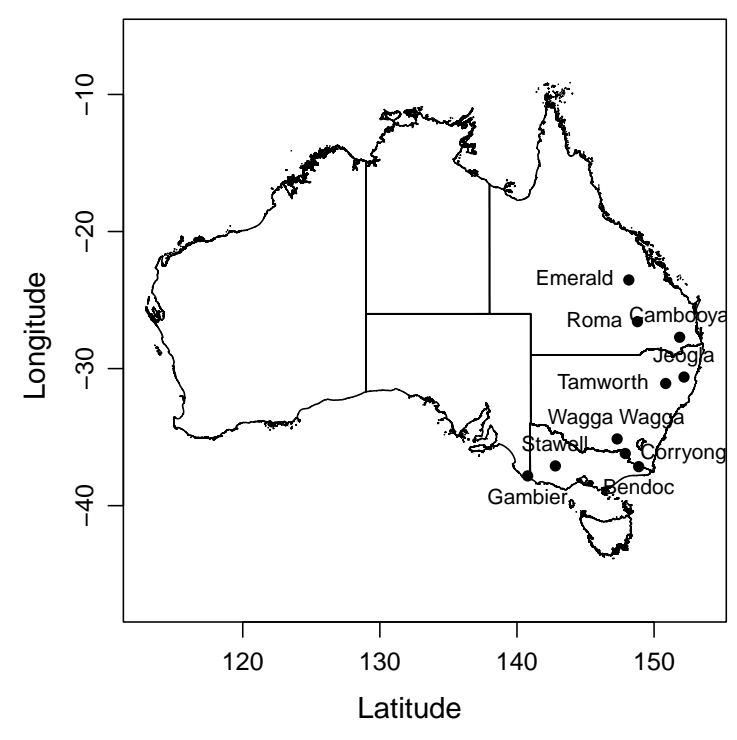

Figure 1. The location of the ten selected sites. 
Attribute data for 10 representative soils with profile characterization up to at least $1.5 \mathrm{~m}$ depth were obtained from the APSOIL soil database (http://www.apsim.info/). The soils differ in texture and plant available water capacity (PAWC), with PAWC ranging from 66 to $261 \mathrm{~mm}$. Although some of the soils may not be found at all the ten study sites, it was assumed that the spatial variation of the soils at any site can give a range of PAWC. In this study, PAWC was calculated as the difference in water contents between drained upper limit (DUL) and the lower limit of wheat crop (LL). DUL is defined as the amount of water that a soil can hold after drainage has been significantly slowed; and LL refers to the lowest water content at which a wheat crop can extract water. All the soil hydraulic parameter values were obtained directly from APSOIL. More detailed information on the ten soils could be found in Wang et al. (2009).

A simplified continuous wheat system was adopted for the analysis. A wheat crop was assumed to be sown every year depending on rainfall and soil water content, which varies for different regions. Crop residues (stem plus leaf) after harvest were retained in the system, and $20 \%$ of them left on the soil surface and the other part was incorporated into the top $20 \mathrm{~cm}$ of soil. We assumed that there was no nitrogen (N) deficiency in the system through applying $25 \mathrm{~kg} \mathrm{~N} \mathrm{ha}^{-1}$ at sowing and $275 \mathrm{~kg} \mathrm{~N} \mathrm{ha}^{-1}$ at stem elongation stage as a top-dressing in the simulation.

\subsection{APSIM simulation}

The APSIM version 7.3 was used for the simulation. APSIM was developed to simulate biophysical process in farming systems. It can simulate crop growth in response to management and environmental changes, and predict long-term consequences of farming practice on the soil resource, such as soil organic carbon. APSIM has been tested and validated in Australia under a wide range of conditions, and has good performance in simulating crop growth, soil water dynamics, soil carbon and nitrogen transformation (Keating et al. 2003, Wang et al. 2003, Luo et al. 2011). APSIM needs daily weather data (rainfall, maximum, minimum and mean temperature, and radiation), and initial soil parameters (e.g., soil $\mathrm{C}$ and nitrogen content, soil bulk density, soil water capacity and soil depth) as inputs. In APSIM, management options can be flexibly specified, which include choice of crop type and cultivar, crop rotation systems, sowing and harvesting rules, tillage, burning, stubble remove or retention, fertilization and irrigation.

At each of the selected sites, the APSIM model was run for 100 years from 1907 to 2006 for each soil with the continuous wheat system as described above. Soil $\mathrm{C}$ content would have reached the steady state at the end of the 100-year simulation. Soil $\mathrm{C}$ content in the top $50 \mathrm{~cm}$ soil profile, wheat biomass and yield, evapotranspiration during the wheat growing season were the output variables used to derive the metamodel.

\subsection{Meta-modelling}

Five sites were randomly chosen from the 10 selected sites to generate the data for developing the metamodel. As the amount of retained residue has been proven to be the dominant factor controlling net soil $\mathrm{C}$ balance (Luo et al. 2011), we firstly tested the relationship between soil $\mathrm{C}$ content at the end of the simulation $\left(C_{\text {content }}\right)$ or the absolute change in soil $\mathrm{C}$ content from 1907 to $2006\left(C_{\text {change }}\right)$ and the mean annual amount of retained residue. Then, we identify the main factors regulating the production of crop residues. We assumed that the soil $\mathrm{C}$ content modelled by APSIM and its change after 100-year simulation could be summarized by initial soil $\mathrm{C}$ content and those parameters determining residue production. The meta-model of $C_{\text {content }}$ and $C_{\text {change }}$ is represented as:

$y=\beta_{0}+\beta_{1} x_{1}+\beta_{2} x_{2}+\ldots+\beta_{n} x_{n}+\varepsilon$

where $y$ is $C_{\text {content }}$ or $C_{\text {change }}$ modelled by APSIM, $x$ 's are the possible driving factors significantly influencing $y, \beta$ 's the regression coefficients, and $\varepsilon$ the residual error.

At the five sites, where the simulation results were not used to develop the metal model, the metal-model was used to simulate $C_{\text {content }}$ and $C_{\text {change }}$ and the results were compared with those from APSIM for each soil at each site. To minimize the uncertainty induced by the residual error $\varepsilon$ that cannot be explained by the meta-model, 100 replicates were generated at each site for each soil using the meta-model under the assumption that the error of its predictions has independent normal distribution. The average of the 100 replicates was compared with that as modeled by APSIM at the five sites.

\section{RESULTS}

At five randomly selected sites (Bendoc, Cambooya, Corryong, Roma and Stawell), the mean annual retained residue explained $83 \%$ and $91 \%$ of the variation of soil $\mathrm{C}$ content at the end of the simulation $\left(C_{\text {content }}\right)$ and soil C changes from 1907 to 2006 ( $\left.C_{\text {change }}\right)$, respectively (Figure 2$)$. At each site, residue 
production was significantly and positively related to plant available water capacity of soil (PAWC) and evapotranspiration in wheat growing season (Figure 3). Therefore, PAWC and evapotranspiration are used as potential drivers determining $C_{\text {content }}$ and $C_{\text {change. }}$. As evapotranspiration closely relates to radiation (R), temperature (T) and precipitation (P), the relationship of $C_{\text {content }}$ and $C_{\text {change }}$ to PAWC, R, T, P in growing season and initial soil $\mathrm{C}$ at each site for each soil was analyzed using stepwise (forward and backward) linear regression analysis. When all the above variables were selected for the model, the AIC (Akaike Information Criterion) got the minimum value. The results are shown in Table 1. Based on the results, the meta-model of $C_{\text {content }}$ and $C_{\text {change }}$ are established as:

$$
\begin{aligned}
& C_{\text {content }}=90.85+0.21 C_{0}+0.043 P A W C-0.012 R+0.023 P-2.65 T+\mathcal{E}, \\
& \text { and } \\
& C_{\text {change }}=90.85-0.79 C_{0}+0.043 P A W C-0.012 R+0.023 P-2.65 T+\varepsilon,
\end{aligned}
$$

where $C_{0}$ is the initial soil $\mathrm{C}$ content, the error $\varepsilon$ has independent normal distributions with mean 0 and standard deviation $6.16 \mathrm{t} \mathrm{ha}^{-1}$ for both $C_{\text {content }}$ and $C_{\text {change. }}$. Both $C_{\text {content }}$ and $C_{\text {change }}$ were significantly related to $P A W C, T$ and $P$; and $C_{0}$ only has significant effect on $C_{\text {change. }}$.
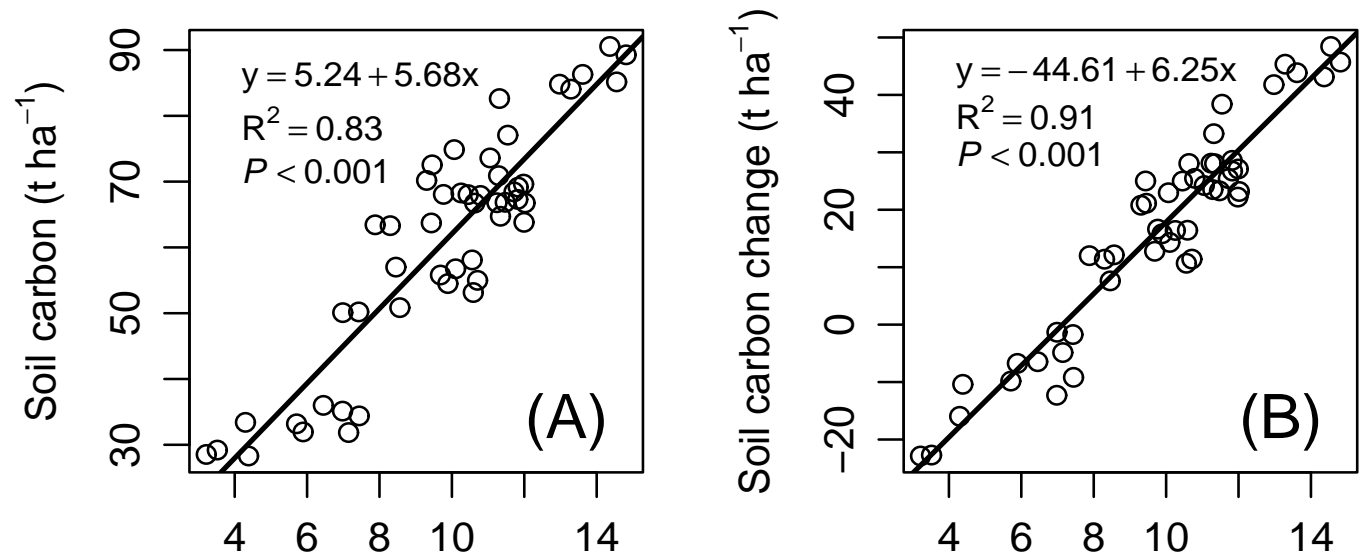

\section{Mean annual retained residue $\left(\mathrm{tha}^{-1}\right)$}

Figure 2. The relationship of soil carbon content $(0-50 \mathrm{~cm})$ at the end of the 100 -year simulation $(A)$ and soil carbon change $(0-50 \mathrm{~cm})$ from 1907 to 2006 (B) to mean annual retained resides at five randomly selected sites (Bendoc, Cambooya, Corryong, Roma and Stawell) from the ten sites.
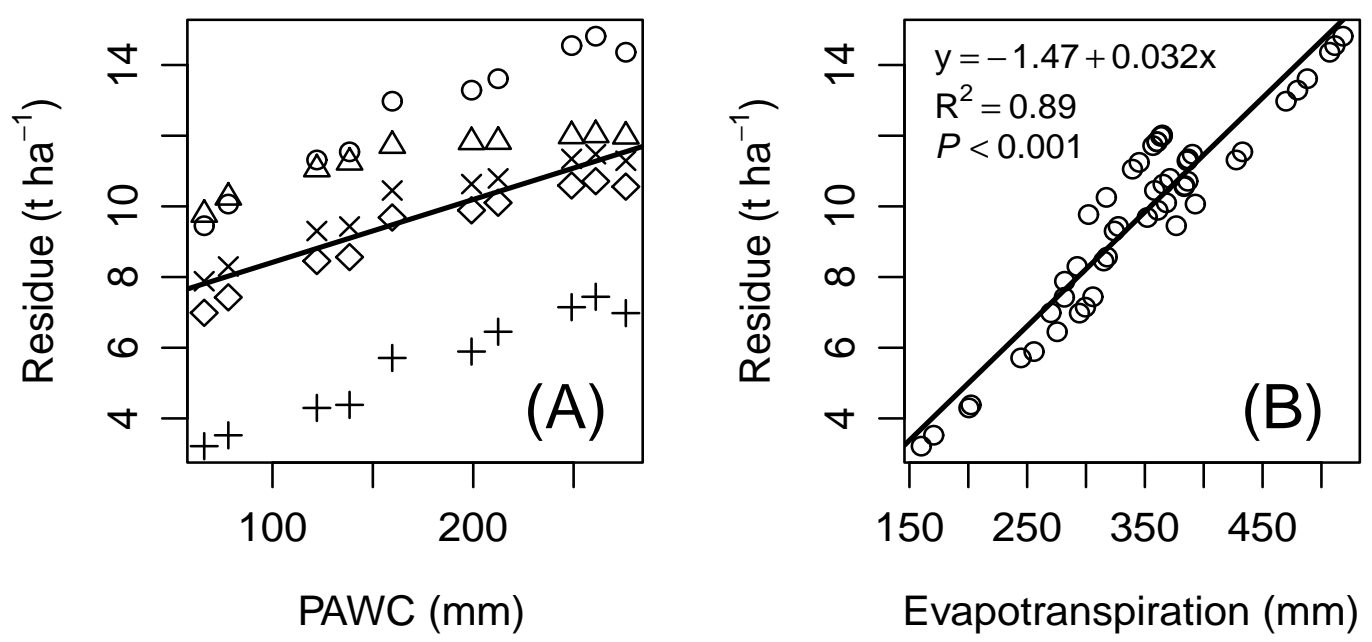

Figure 3. The relationship of mean annual residue production to plant available water capacity of soil (A) and mean evapotranspiration in wheat growing season (B) at five randomly selected sites from the ten sites.

Different symbols in (A) show the values at five sites. Thick black line shows the regression line using complete pooling of all data at five sites. 
Table 1. Stepwise regression analysis of the effect of initial soil carbon content $\left(C_{0}\right)$, plant available water capacity of soil (PAWC), radiation (R), mean annual temperature $(\mathrm{T})$ and precipitation $(\mathrm{P})$ on soil carbon content at the end of the 100-year simulation $\left(C_{\text {content }}\right)$ and the soil carbon change from 1907 to 2006

$$
\left(C_{\text {change }}\right) \text {. }
$$

\begin{tabular}{ccccccc}
\hline \multirow{2}{*}{ Effect } & \multicolumn{5}{c}{$C_{\text {content }}$} & \multicolumn{3}{c}{$C_{\text {change }}$} \\
\cline { 2 - 7 } & Coefficient $(\beta)$ & $t$ value & $P>|t|$ & Coefficient $(\beta)$ & $t$ value & $P>|t|$ \\
\hline Intercept & 90.85 & 6.96 & $<0.0001$ & 90.85 & 6.96 & $<0.0001$ \\
$C_{0}\left(x_{1}\right)$ & 0.21 & 1.44 & 0.15 & -0.79 & -5.56 & $<0.0001$ \\
$P A W C\left(x_{2}\right)$ & 0.043 & 4.14 & $<0.0001$ & 0.043 & 4.14 & 0.00018 \\
$R\left(x_{3}\right)$ & -0.012 & -3.68 & 0.00039 & -0.012 & -3.68 & 0.00039 \\
$T\left(x_{4}\right)$ & -2.65 & -6.54 & $<0.0001$ & -2.65 & -6.54 & $<0.0001$ \\
$P\left(x_{5}\right)$ & 0.023 & 1.84 & 0.069 & 0.023 & 1.84 & 0.069 \\
Residual Error $(\varepsilon)$ & \multicolumn{7}{c}{6.16} & & 0.16 & $0.89(P<0.0001)$ \\
Whole model $R^{2}$ & \multicolumn{3}{c}{$0.87(P<0.0001)$} & &
\end{tabular}
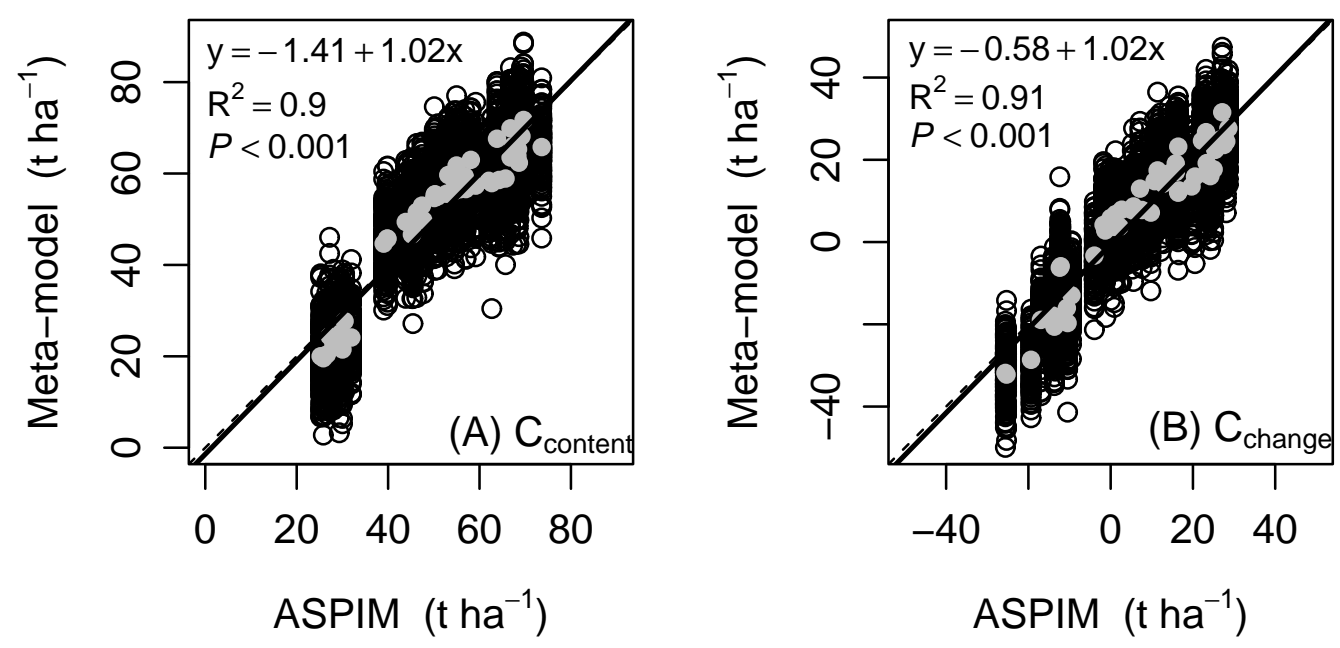

Figure 4. Comparison of (A) soil carbon content $(0-50 \mathrm{~cm})$ at the end of the 100-year simulation (Ccontent) and (B) soil carbon change $(0-50 \mathrm{~cm})$ from 1907 to 2006 (Cchange) as predicted by the metamodels with that simulated by APSIM at five sites (Emerald, Gambier, Jeogla, Tamworth and Wagga Wagga, see details in the text). Open circles (०) show the 100 replicates; and filled grey circles $(\bullet)$ show their means at each site for each soil. The thick lines show the regression line based on means $(\bullet)$. Dashed lines show the 1:1 line.

The variation of $C_{\text {content }}$ and $C_{\text {change }}$ as simulated by APSIM could be well explained by the two meta-models (i.e., eqn (2) and (3) respectively, Table 1). Figure 3 shows the prediction from the meta-models for $C_{\text {content }}$ and $C_{\text {change }}$ at the other five sites (Corryong, Emerald, Gambier, Tamworth and Wagga Wagga). The predictions had some variability at a specific site for a specific soil because of the residual error of the two models (Figure 4). However, on average, the two meta-models could explain $90 \%$ and $91 \%$ of the variation of $C_{\text {content }}$ and $C_{\text {change }}$ respectively, as simulated by APSIM (Figure 4).

\section{DISCUSSION AND CONCLUSIONS}

The results presented here indicate meta-modelling could well capture the simulated soil C changes simulated by process-based models, by using several easily obtainable parameters including initial soil C content, plant available water capacity of soil, temperature and rainfall. This is consistent with the findings of Beer et al. (2010), who found that local and global gross primary productivity (GPP, the source of soil C) could be quantified by general relationships between GPP and several drivers such as temperature, rainfall, and biome type. Although our simulations were not based on real observed data, the results show that it is possible to simplify the modelling through meta-models to capture the dynamics of soil $\mathrm{C}$ across different 
regions. The ten sites span the zone of wheat-belt of eastern Australia and cover the most of the climate types in this region; the ten soils also represent the possible soil types with different texture and hydrological properties which are dominant factor controlling crop production thereby the subsequent soil $\mathrm{C}$ dynamics. Compared with the process-based model APSIM, the meta-model significantly reduces the requirement of input data. The meta-model would be easily used across regions or continent.

\section{ACKNOWLEGMENTS}

The funding support from the CSIRO Integrated Carbon Program (ICP) is gratefully acknowledged.

\section{REFERENCES}

Beer, C., M. Reichstein, E. Tomelleri, P. Ciais, M. Jung, N. Carvalhais, C. Rodenbeck, M. A. Arain, D. Baldocchi, G. B. Bonan, A. Bondeau, A. Cescatti, G. Lasslop, A. Lindroth, M. Lomas, S. Luyssaert, H. Margolis, K. W. Oleson, O. Roupsard, E. Veenendaal, N. Viovy, C. Williams, F. I. Woodward, and D. Papale. 2010. Terrestrial Gross Carbon Dioxide Uptake: Global Distribution and Covariation with Climate. Science 329:834-838.

Falloon, P. and P. Smith. 2003. Accounting for changes in soil carbon under the Kyoto Protocol: need for improved long-term data sets to reduce uncertainty in model projections. Soil Use and Management 19:265-269.

Keating, B. A., P. S. Carberry, G. L. Hammer, M. E. Probert, M. J. Robertson, D. Holzworth, N. I. Huth, J. N. G. Hargreaves, H. Meinke, Z. Hochman, G. McLean, K. Verburg, V. Snow, J. P. Dimes, M. Silburn, E. Wang, S. Brown, K. L. Bristow, S. Asseng, S. Chapman, R. L. McCown, D. M. Freebairn, and C. J. Smith. 2003. An overview of APSIM, a model designed for farming systems simulation. European Journal of Agronomy 18:267-288.

Kleijnen, J. P. C., S. M. Sanchez, T. W. Lucas, and T. M. Cioppa. 2005. A user's guide to the brave new world of designing simulation experiments. Informs Journal on Computing 17:263-289.

Kleijnen, J. P. C. and R. G. Sargent. 2000. A methodology for fitting and validating metamodels in simulation. European Journal of Operational Research 120:14-29.

Luo, Z., E. Wang, O. J. Sun, C. J. Smith, and M. E. Probert. 2011. Modeling long-term soil carbon dynamics and sequestration potential in semi-arid agro-ecosystems. Agricultural and Forest Meteorology DOI:10.1016/j.agrformet.2011.1006.1011.

Mahecha, M. D., M. Reichstein, N. Carvalhais, G. Lasslop, H. Lange, S. I. Seneviratne, R. Vargas, C. Ammann, M. A. Arain, A. Cescatti, I. A. Janssens, M. Migliavacca, L. Montagnani, and A. D. Richardson. 2010. Global Convergence in the Temperature Sensitivity of Respiration at Ecosystem Level. Science 329:838-840.

Ogle, S. M., F. J. Breidt, M. Easter, S. Williams, K. Killian, and K. Paustian. 2010. Scale and uncertainty in modeled soil organic carbon stock changes for US croplands using a process-based model. Global Change Biology 16:810-822.

Saby, N. P. A., P. H. Bellamy, X. Morvan, D. Arrouays, R. J. A. Jones, F. G. A. Verheijen, M. G. Kibblewhite, A. Verdoodt, J. Berenyiuveges, A. Freudenschuss, and C. Simota. 2008. Will European soil-monitoring networks be able to detect changes in topsoil organic carbon content? Global Change Biology 14:2432-2442.

Santos, I. R. and P. R. Santos. 2007. Simulation metamodels for modeling output distribution parameters. Proceedings of the 2007 Winter Simulation Conference, Vols 1-5:889-897.

Wang, E., H. Cresswell, J. Xu, and Q. Jiang. 2009. Capacity of soils to buffer impact of climate variability and value of seasonal forecasts. Agricultural and Forest Meteorology 149:38-50.

Wang, E., E. van Oosterom, H. Meinke, S. Asseng, M. Robertson, N. Huth, B. Keating, and M. Probert. 2003. The new APSIM-Wheat Model-performance and future improvements.in Solutions for a better environment. Australian Society of Agronomy, Geelong, Victoria, Australia. 